\title{
Оптические свойства квазиобъемных кристаллов нитрида галлия со структурой высокоориентированной текстуры
}

\author{
(C) М.Г. Мынбаева ${ }^{1}$, А.Н. Смирнов ${ }^{1}$, К.Д. Мынбаев ${ }^{1,2}$ \\ ${ }^{1}$ Физико-технический институт им. А.Ф. Иоффе Российской академии наук, \\ 194021 Санкт-Петербург, Россия \\ ${ }^{2}$ Университет ИТМО, \\ 197101 Санкт-Петербург, Россия \\ E-mail: mgm@mail.ioffe.ru
}

Поступила в Редакцию 10 марта 2021 г.

В окончательной редакции 22 марта 2021 г.

Принята к публикации 22 марта 2021 г.

\begin{abstract}
Представлены результаты исследования оптических свойств образцов нитрида галлия со структурой высокоориентированной текстуры, выращенных без использования традиционных полупроводниковых или сапфировых подложек. Показано, что дефекты упаковки, содержащиеся в блоках GaN-текстуры исследованного материала, представляют собой самоорганизованные гетерополитипные наноструктуры, и эффективная люминесценция в ультрафиолетовой области спектра, связанная с дефектами упаковки в базисной плоскости типа $I_{1}$, определяется оптическими переходами экситонов, локализованных вблизи таких естественных дефектов монокристаллического объема блоков $\mathrm{GaN}$-текстуры.
\end{abstract}

Ключевые слова: нитрид галлия, дефекты упаковки, люминесценция.

DOI: 10.21883/FTP.2021.07.51015.9648

Светоизлучающие наноструктуры, образованные дефектами кристаллической решетки в полупроводниках, в настоящее время рассматриваются как перспективные компоненты квантовых технологий [1]. В частности, дефекты упаковки (ДУ) в нитриде галлия $(\mathrm{GaN})$ при комнатной температуре $(300 \mathrm{~K})$ могут являться эффективными источниками излучения в широком спектральном диапазоне - от ультрафиолетового (УФ) до инфракрасного. Люминесценция, связанная с ДУ, неоднократно наблюдалась в легированных и номинально нелегированных эпитаксиальных пленках $\mathrm{GaN}$, выращенных на различных типах подложек (см., например, [2-4]). В настоящей работе мы сообщаем о люминесценции, связанной с дефектами упаковки в базисной плоскости (БДУ) в квазиобъемном $\mathrm{GaN}$ со структурой высокоориентированной вюрцитной текстуры. Пластины текстурированного $\mathrm{GaN}$ миллиметровой толщины были получены путем осаждения на керамический пьедестал из нитрида бора (BN) в реакторе, предназначенном для проведения хлоридгидридной эпитаксии (ХГЭ) без использования традиционных подложек из полупроводниковых материалов или сапфира [5]. Процесс нуклеации $\mathrm{GaN}$ на керамике имел существенные отличия от процесса нуклеации слоев при эпитаксии на традиционных подложках и происходил с участием жидкой фазы галлия. Это способствовало тому, что после окончания процесса роста пластины выращенного материала свободно отделялись от керамического пьедестала без необходимости привлечения каких-либо дополнительных разделительных (так называемых lift-off) технологий. Было установлено, что $\mathrm{GaN}$ со структурой высокоориентированной текстуры обладает особыми эмиссионными свойствами в широком диапазоне температур, от криогенных до комнатной [6].
Для исследования особенностей кристаллической структуры и оптических свойств материала из пластин были вырезаны образцы размером $1.1 \times 1.1 \mathrm{~cm} \mathrm{и}$ толщиной от 100 до 200 мкм, которые представляли собой материал верхнего, среднего и нижнего объема пластин GaN. Кроме того, были изучены образцы поперечных срезов пластин толщиной 1.5-3 мм. Методом порошковой рентгеновской дифракции (РД) были проведены исследования степени однородности структуры и фазового состава материала пластин в различных областях его объема [7]. Взаимная ориентация блоков текстуры и их дефектная структура были изучены методом просвечивающей электронной микроскопии (ПЭМ) с использованием микроскопов Philips EM-420 (ускоряющее напряжение 80 кВ, разрешение $5 \AA$ ) и Jeol JEM-2100F (ускоряющее напряжение 200 кB, разрешение $2 \AA$ ). В результате проведенных взаимодополняющих структурных исследований было установлено, что нижний объем материала представлял собой текстуру со смешанным фазовым составом гексагонального полярного и полуполярного нитрида галлия, $c-\mathrm{GaN}$ и $m-\mathrm{GaN}$ соответственно. Такой тип структуры сохранялся до толщины выращиваемого материала $\sim 300-700$ мкм. Вышележащий объем представлял собой высоко упорядоченную текстуру GaN c преимущественной ориентацией вдоль $c$-оси в гексагональной решетке. Выявленные в результате проведения РД и ПЭМ исследований особенности структуры материала пластин $\mathrm{GaN}$ указывали на наиболее вероятный механизм его формирования, как на классический механизм „эволюционного отбора“ (англ. „evolutionary selection“), предложенный в 1967г. А. ван дер Дрифтом и основанный на принципе саморегуляции роста текстурированных кристаллов [8]. 
Согласно модели ван дер Дрифта, преимущественная ориентация структуры материала, формирующегося над разориентированным зародышевым слоем, определяется скоростью вертикального роста отдельных блоков. В результате такого „геометрического“ отбора блоки, растущие с максимальной скоростью вдоль или в направлении, близком к оси, перпендикулярной подложке $(c-\mathrm{GaN})$, вырастают наиболее крупными. Блоки, растущие вдоль оси, наклонно ориентированной по отношению к нормали $(m-\mathrm{GaN})$, блокируются в объеме материала соседними блоками, имеющими лучшее „выравнивание“ вдоль вертикальной оси роста, создавая, таким образом, феномен „эволюционного отбора“.

Представления об особенностях структуры материала пластин объемного $\mathrm{GaN}$ были подтверждены и дополнены результатами их исследований методом спектроскопии комбинационного рассеяния света (КРС). Спектры КРС были записаны в геометрии обратного рассеяния при комнатной температуре на спектрометре Horiba Jobin-Yvon T64000 (пр-во Франция), оснащенном конфокальным микроскопом Olympus BX41, использовавшимся для фокусировки лазерного луча в пятно диаметром до 1 мкм. В качестве источника возбуждения использовался лазер Nd:YAG с $\lambda=532$ нм (Torus 532, пр-во Laser Quantum Ltd, Великобритания).

Согласно правилам отбора, в спектрах КРС монокристаллического $\mathrm{GaN}$ гексагональной модификации (пространственная группа симметрии $\left.C_{6 V}^{4} P 6_{3} m c\right)$, выращенного вдоль гексагональной оси $c$, должны наблюдаться шесть разрешенных оптических фононов [9]: фононы $E_{2}($ low $)$ и $E_{2}($ high $)$, которые разрешены в геометриях рассеяния $z(x x) \bar{z}, z(y x) \bar{z}$ и $y(x x) \bar{y} ;$ фононы $A_{1}(\mathrm{TO})-$ в геометриях $x(z z) \bar{x}$ и $x(y y) \bar{x}$; фононы $E_{1}(\mathrm{TO})-$ в геометрии $x(y z) \bar{x}$; фононы $A_{1}(\mathrm{LO})$ - в геометрии рассеяния $z(x x) \bar{z}$; и фононы $E_{1}(\mathrm{LO})-$ в геометрии $x(y x) y$. Здесь $z$ - направление вдоль гексагональной оси $c$, а $x$ и $y$ являются равнозначными и взаимно ортогональными направлениями в базовой плоскости кристаллической решетки $\mathrm{GaN}$, перпендикулярной $c$-оси.

На рис. 1 представлен типичный спектр КРС (геометрия рассеяния $z(x x) \bar{z})$ образца среднего объема пластин толщиной 700 мкм, в котором наблюдаются три разрешенных правилами отбора линии, относящиеся к фононам симметрии $E_{2}$ (low), $E_{2}$ (high) и $A_{1}(\mathrm{LO})$. Кроме разрешенных линий, в спектре присутствует запрещенная линия симметрии $A_{1}(\mathrm{TO})$ существенно меньшей интенсивности. Проявление этой фононной линии в использованной геометрии съемки возможно в том случае, когда гексагональная ось исследуемого материала находится под небольшим углом к направлению распространения лазерного луча. Из анализа полученных спектров и из относительного соотношения интенсивностей наблюдаемых спектральных линий следует, что преимущественная ориентация в исследованном материале совпадает с направлением гексагональной оси $c$. Полученные результаты находятся в согласии с данными

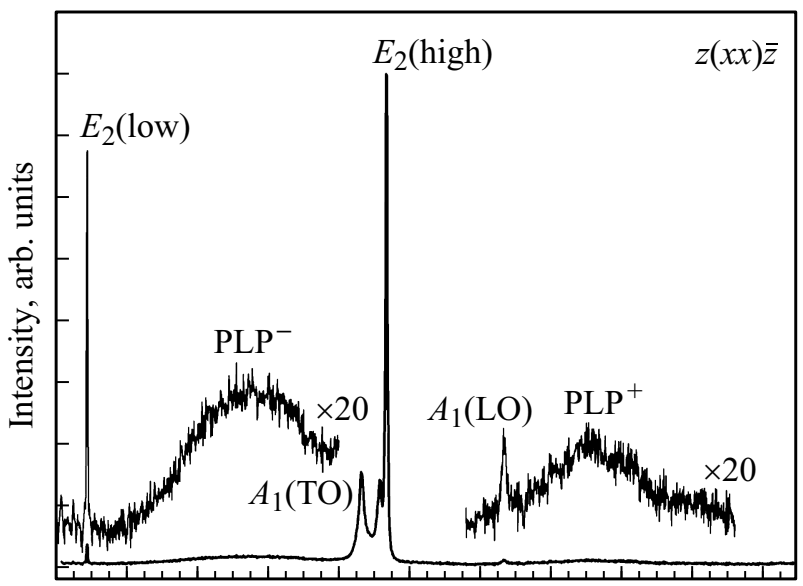

10020030040050060070080090010001100

Raman shift, $\mathrm{cm}^{-1}$

Рис. 1. Спектр КРС образца $\mathrm{GaN}$ толщиной 700 мкм. $T=300 \mathrm{~K}$.

ПЭМ и рентгенофазового анализа структуры материала, также показавшими наличие разориентированных блоков на ранних стадиях формирования $\mathrm{GaN}$ [0001]текстуры.

В спектрах КРС также присутствовали полосы, по положению соответствующие связанным плазмонLO-фононным модам $\left(\mathrm{PLP}^{-}\right.$и $\left.\mathrm{PLP}^{+}\right)$. K образованию связанных фонон-плазмонных мод приводит взаимодействие продольных оптических фононов (LO) с плазмонами свободных носителей. Ширина на половине высоты линии $(F W H M)$ и частотное положение этих мод определяется концентрацией свободных электронов и их подвижностью [10]. Согласно сделанным оценкам, концентрация свободных электронов в образце материала нижнего объема пластин $\mathrm{GaN}$ составляла $\sim(3-5) \cdot 10^{18} \mathrm{~cm}^{-3}$, а подвижность была $120 \mathrm{~cm}^{2} /(\mathrm{B} \cdot \mathrm{c})$. В спектре образца толщиной 700 мкм наряду со связанными плазмон-LO-фононными модами наблюдалась линия в области неэкранированного LO-фонона. Это указывает на то, что с увеличением толщины материала наблюдается тенденция к снижению концентрации свободных носителей до уровня $\sim 1 \cdot 10^{17} \mathrm{~cm}^{-3}$, характерного для эпитаксиальных слоев сходной толщины, выращенных ХГЭ на сапфире [11]. Оценки величины структурных напряжений были сделаны с использованием постоянных фононного деформационного потенциала $[12,13]$. Положение линии $E_{2}$ (high) на частоте $567.6-567.4 \mathrm{~cm}^{-1}$ в спектрах, полученных от образцов среднего и верхнего объема пластин $\mathrm{GaN}$, близки к положению фонона той же симметрии в спектрах образцов $\mathrm{GaN}$, свободных от структурных напряжений $\left(567.8 \mathrm{~cm}^{-1}\right)[12]$.

При проведении комплексных исследований была установлена корреляция оптических свойств со спецификой дефектной структуры материала. Результаты ПЭМ исследований показали, что отличительной 


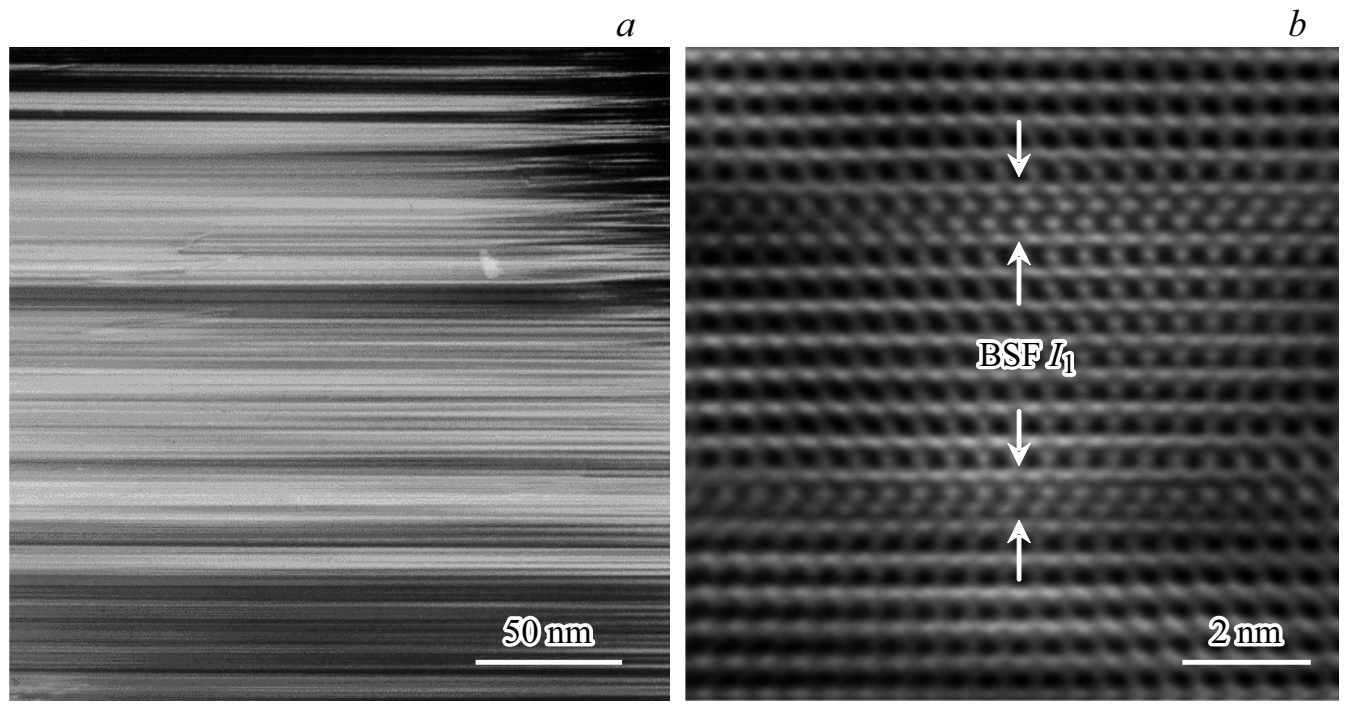

Рис. 2. ПЭМ-изображения БДУ (BSF) в исследованном материале: поперечный срез образца толщиной 1.5 мм с БДУ $I_{1}(a)$, изображение дефектов упаковки, полученное в режиме высокого разрешения $(b)$.
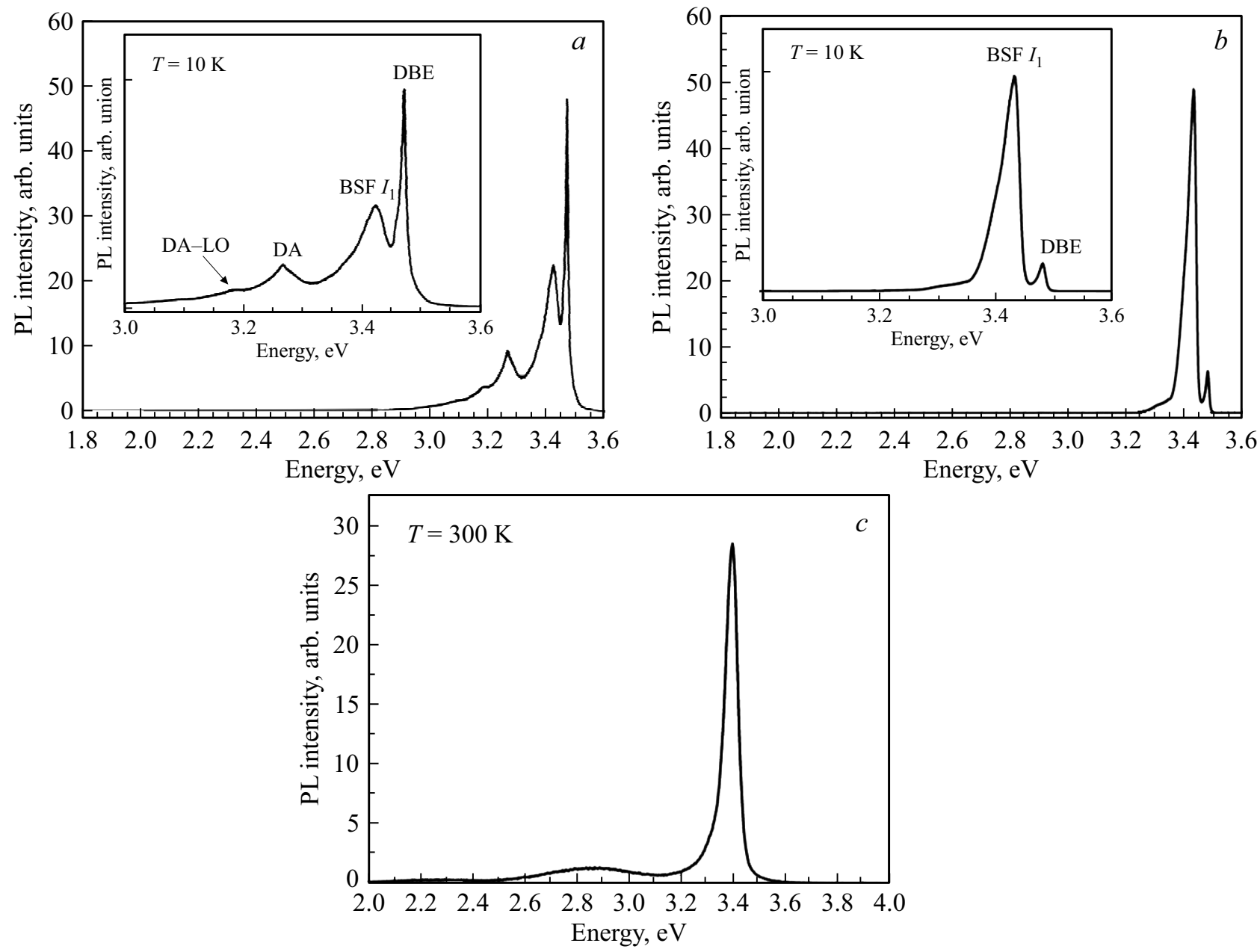

Рис. 3. Спектры низкотемпературной ФЛ $(T=10 \mathrm{~K})$ образцов текстурированного GaN с плотностью БДУ $I_{1} \sim 10^{4} \mathrm{~cm}^{-1}(a)$ и $I_{1} \sim 10^{6} \mathrm{~cm}^{-1}(b)$ (на вставках приведены детализации спектров в диапазоне энергий 3.0-3.6 эВ), и спектр высокотемпературной ФЛ $(T=300 \mathrm{~K})$ образца с плотностью БДУ $I_{1} \sim 10^{6} \mathrm{~cm}^{-1}(c)$. 
особенностью дефектной структуры текстурированного $\mathrm{GaN}$ было наличие БДУ типа $I_{1}$ с высокой плотностью, на уровне $10^{4}-10^{6} \mathrm{~cm}^{-1}$ [14]. На рис. 2 показано ПЭМизображение поперечного среза блока текстуры, содержащего БДУ, и ПЭМ-изображение БДУ, полученное при более высоком разрешении. Толщина представленных на рис. 2 БДУ соответствовала одному би-слою, что по классификации работы [2] позволило отнести их к типу $I_{1}$.

На рис. 3 представлены спектры низкотемпературной $(T=10 \mathrm{~K})$ и комнатной $(T=300 \mathrm{~K})$ ФЛ образцов текстурированного $\mathrm{GaN}$ с различной плотностью БДУ, записанные при возбуждении $\mathrm{He}-\mathrm{Cd}$-лазером (пр-во АO „Плазма“, Россия) с длиной волны 325 нм. На рисунке видно, что в спектрах присутствуют полосы рекомбинации экситона, связанного на нейтральном доноре (DBE), и рекомбинации донорно-акцепторных пар (DA) c положением максимума на 3.27 э и их фононными (DA-LO) репликами, а также пик с энергией $3.42 \ni \mathrm{B}$, положение которого соответствует люминесценции экситона, связанного на БДУ типа $I_{1}$ в гексагональной решетке $\mathrm{GaN}$ [2]. Из сравнения спектров, приведенных на рис. 3, $a$ и $b$ видно, что с увеличением плотности ДУ изменяется соотношение интенсивностей полос излучения DBE и экситонов, связанных на БДУ. В спектрах ФЛ образцов с плотностью БДУ $I_{1} \sim 10^{6} \mathrm{~cm}^{-1}$ соотношение интенсивностей полосы излучения DBE и полосы люминесценции с максимумом 3.42 эВ составляло $1 / 10$, что указывало на явную зависимость интенсивности пика от плотности БДУ. В высокотемпературных спектрах ФЛ доминировал пик с максимумом, соответствовавшим энергии 3.40 эВ (рис. $3, c$ ).

С учетом полученных данных было сделано предположение, что наблюдавшиеся особенности спектров люминесценции могут быть описаны в рамках модели $\mathrm{GaN}$ c „неклассическими“ квантовыми ямами, предложенной Ребане идр. [15] и позднее развитой в работе [16]. Данная модель предполагает, что ДУ в кристаллической структуре гексагонального $\mathrm{GaN}$ представляют собой наноразмерные гетерополитипные структуры с атомноплоскими интерфейсами, и в силу своей двумерной природы являются естественными квантовыми ямами. Эффективная люминесценция в УФ части спектра возникает в результате излучательной рекомбинации экситонов, локализованных на внутренних границах БДУ. Предложенная модель была верифицирована результатами ряда экспериментальных работ, обзор которых представлен в работе [2]. Как было показано, БДУ в гексагональном $\mathrm{GaN}$ являются кубическими включениями, и положение линий эмиссии, связанной с БДУ различных типов, определяется их структурой [2]:

- БДУ $I_{1}-3.40-3.42$ эВ (толщина соответствует одному молекулярному слою (би-слою) или $0.5 c_{0}$, где $c_{0}$ - параметр решетки в направлении [0001]);

- БДУ $I_{2}-3.32-3.36$ эВ (толщина $\left.=c_{0}\right)$;

- БДУ $E-3.29$ эВ (толщина $\left.=15 c_{0}\right)$;
- сегменты кубической фазы - 3.0-3.27 эВ (толщина до 3 нм).

Согласно представленной классификации, положение пика излучения позволяет идентифицировать ответственные за него дефекты как БДУ типа $I_{1}$.

Таким образом, было установлено, что плотность доминирующих дефектов кристаллической структуры текстурированного $\mathrm{GaN}$, дефектов упаковки типа $I_{1}$, определяет его необычные эмиссионные свойства в УФ области спектра в широком температурном диапазоне, от 10 до $300 \mathrm{~K}$. В этом проявляется одно из важных отличий нового текстурированного материала от традиционного эпитаксиального $\mathrm{GaN}$, где увеличение плотности доминирующих дефектов - дислокаций, являющихся центрами безызлучательной рекомбинации, - приводит к снижению эффективности люминесценции. Возможность получения „объемного“ $\mathrm{GaN}$ в новой структурной модификации позволяет расширить сферу применения данного материала: из области классической оптоэлектроники, построенной на эпитаксиальных наноструктуpax, в перспективную область неклассических эффективных излучателей, эмиссия света которых определяется оптическими переходами экситонов, локализованных на самоорганизованных наноструктурах, образованных естественными дефектами в монокристаллическом объеме полупроводника.

\section{Конфликт интересов}

Авторы заявляют, что у них нет конфликта интересов.

\section{Список литературы}

[1] D.S. Chen, W.B. Gao. J. Semicond., 40, 070301 (2019).

[2] J. Lähnemann, U. Jahn, O. Brandt, T. Flissikowski, P. Dogan, H.T. Grahn. J. Phys. D: Appl. Phys., 47, 423001 (2014).

[3] Y. Zhang, R.M. Smith, L. Jiu, J. Bai, T. Wan. Sci. Rep., 9, 9735 (2019).

[4] А.В. Соломникова, В.Н. Бессолов, Е.В. Коненкова, Т.А. Орлова, С.Н. Родин, Н.В. Середова, М.П. Щеглов, Д.С. Кибалов, В.К. Смирнов. ФТП, 53, 1006 (2019).

[5] М.Г. Мынбаева, А.И. Печников, А.А. Ситникова, Д.А. Кириленко, А.А. Лаврентьев, Е.В. Иванова, В.И. Николаев. Письма ЖТФ, 41 (5), 84 (2015).

[6] M.G. Mynbaeva, E.V. Ivanova, D.A. Kirilenko, A.N. Smirnov, K.D. Mynbaev. J. Phys. Conf. Ser., 1697, 012064 (2020).

[7] M. Dermeneva, D. Muravijova, M. Mynbaeva, V. Bougrov, M. Yagovkina. J. Phys. Conf. Ser., 1124, 081008 (2018).

[8] A. van der Drift. Phil. Res. Rep., 22, 267 (1967).

[9] C.A. Arguello, D.L. Rousseau, S.P.S. Porto. Phys. Rev., 181 (3), 1351 (1969).

[10] V.V. Emtsev, V.Yu. Davydov, V.V. Kozlovskii, V.V. Lundin, D.S. Poloskin, A.N. Smirnov, N.M. Shmidt, A.S. Usikov, J. Aderhold, H. Klausing, D. Mistele, T. Rotter, J. Stemmer, O. Semchinova, J. Graul. Semicond. Sci. Technol., 15, 73 (2000).

[11] М.Г. Мынбаева, А.И. Печников, А.Н. Смирнов, Д.А. Кириленко, С.Ч. Рауфов, А.А. Ситникова, М.А. Одноблюдов, В.Е. Бугров, К.Д. Мынбаев, В.И. Николаев, А.Е. Романов. Физ. мех. матер., 29 (1), 24 (2016). 
[12] V.Yu. Davydov, N.S. Averkiev, I.N. Goncharuk, D.K. Nelson, I.P. Nikitina, A.S. Polkovnikov, A.N. Smirnov, M.A. Jacobson, O.K. Semchinova. J. Appl. Phys., 82, 5097 (1997).

[13] Yu.V. Melnik, K.V. Vassilevski, I.P. Nikitina, A.I. Babanin, V.Yu. Davydov, V.A. Dmitriev. MRS Internet J. Nitride Semicond. Res., 2, e39 (1997).

[14] Д.А. Кириленко, А.В. Кремлева, А.А. Ситникова, А.В. Кремлева, М.Г. Мынбаева, В.И. Николаев. Письма ЖТФ, 40 (24), 60 (2014).

[15] Y.T. Rebane, Y.G. Shreter, M. Albrecht. Phys. Status Solidi A, 164, 141 (1997).

[16] I. Tischer, M. Hocker, B. Neuschl, M. Madel, M. Feneberg, M. Schirra, M. Frey, M. Knab, P. Maier, T. Wunderer, R.A.R. Leute, J. Wang, F. Scholz, J. Biskupek, J. Bernhard, U. Kaiser, U. Simon, L. Dieterle, H. Groiss, E. Müller, D. Gerthsen, K. Thonke. J. Mater. Res., 30, 2977 (2015).

Редактор А.Н. Смирнов

\title{
Optical properties of quasi-bulk gallium nitride crystals with highly oriented texture structure
}

\author{
M.G. Mynbaeva ${ }^{1}$, A.N. Smirnov ${ }^{1}$, K.D. Mynbaev ${ }^{\mathbf{1 , 2}}$
}

1 loffe Institute, 194021 St. Petersburg, Russia

2 ITMO University, 197101 St. Petersburg, Russia

Abstract The results of a study of the optical properties of gallium nitride samples with a highly oriented texture structure grown without the use of traditional semiconductor or sapphire substrates are presented. It is shown that the stacking faults contained in the GaN blocks of the texture of the studied material are self-organized heteropolytype nanostructures, and that the effective luminescence in the ultraviolet spectral region associated with stacking faults $I_{1}$ in the basal plane is determined by optical transitions of excitons localized near such natural defects in the single-crystalline bulk of the blocks of the GaN texture. 